\title{
Antiproliferative and apoptosis-inducing effects of maslinic and oleanolic acids, two pentacyclic triterpenes from olives, on HT-29 colon cancer cells
}

\author{
M. Emília Juan ${ }^{1}$, Joana M. Planas ${ }^{1}$, Valentina Ruiz-Gutierrez ${ }^{2}$, Hannelore Daniel ${ }^{3}$ and Uwe Wenzel ${ }^{4}$ \\ ${ }^{1}$ Departament de Fisiologia, Facultat de Farmàcia, Universitat de Barcelona, Av. Joan XXIII s/n, Barcelona E-08028, Spain \\ ${ }^{2}$ Nutrición y Metabolismo Lipídico, Instituto de la Grasa, CSIC, Av. Padre Garcia Tejero 4, Sevilla E-41012, Spain \\ ${ }^{3}$ Molecular Nutrition Unit, Department of Food and Nutrition, Technical University of Munich, Am Forum 5, Freising D-85350, Germany \\ ${ }^{4}$ Molecular Nutrition Research, Interdisciplinary Research Center, Justus-Lieberg-University of Giessen, Heinrich-Buff Ring 26-32, \\ Giessen D-35392, Germany
}

(Received 15 May 2007 - Revised 23 October 2007 - Accepted 25 October 2007 - First published online 26 February 2008)

\begin{abstract}
We have previously reported the anticarcinogenic effects of an olive fruit extract composed of pentacyclic triterpenes, the main components of which are maslinic acid $(73.25 \%)$ and oleanolic acid $(25.75 \%)$. Here we examined the effects of the individual components on proliferation, necrosis and apoptosis rates by fluorescence-based techniques in human HT-29 colon cancer cells. Oleanolic acid showed moderate antiproliferative activity, with an $\mathrm{EC}_{50}$ of 160.6 (SE 10.6) $\mu \mathrm{mol} / 1$, and moderate cytotoxicity at high concentrations $(\geq 250 \mu \mathrm{mol} / \mathrm{l})$. On the other hand, maslinic acid inhibited cell growth with an $\mathrm{EC}_{50}$ of 101.2 (SE 7.8) $\mu \mathrm{mol} / \mathrm{l}$, without necrotic effects. Oleanolic acid, which lacks a hydroxyl group at the carbon 2 position, failed to activate caspase- 3 as a prime apoptosis protease. In contrast, maslinic acid increased caspase-3-like activity at 10, 25 and $50 \mu \mathrm{mol} / 1$ by 3-, 3.5- and 5-fold over control cells, respectively. The detection of ROS in the mitochondria, which serve as pro-apoptotic signal, evidenced the different bioactivity of the two triterpenes. Confocal microscopy analysis revealed that maslinic acid generated superoxide anions while oleanolic acid-treated cells did not differ from the control. Completion of apoptosis by maslinic acid was confirmed microscopically by the increase in plasma membrane permeability, and detection of DNA fragmentation. In conclusion, the anticancer activity observed for olive fruit extracts seems to originate from maslinic acid but not from oleanolic acid. Maslinic acid therefore is a promising new compound for the chemoprevention of colon cancers.
\end{abstract}

Maslinic acid: Oleanolic acid: Apoptosis: HT-29 cells

Olives and olive oil are a major part of the traditional Mediterranean diet, which has been associated with a low incidence and prevalence of cancer ${ }^{(1,2)}$. In support of a hypothesis that constituents of olives may contribute to the cancer protective activity of this diet we recently reported that an extract from the skin of olive fruits composed of maslinic acid (73.25\%) and oleanolic acid $(25.75 \%)$ inhibited proliferation and effectively induced apoptosis in HT-29 human colon cancer cells ${ }^{(3)}$. Maslinic and oleanolic acids (Fig. 1) are pentacyclic triterpenes present in the skin of olive fruits ${ }^{(4,5)}$. These non-nutritive dietary constituents can be detected in olive oils ${ }^{(4)}$ with higher concentrations in olive pomace oils, also known as 'orujo oil', than in virgin olive oils ${ }^{(6)}$. In olive fruits maslinic and oleanolic acids are present at concentrations of 681 (SE 63) $\mathrm{mg} / \mathrm{kg}$ and 420 (SE 20) mg/kg, respectively ${ }^{(6)}$. The hydrolytic processes that take place in the fruit during extraction facilitate the release of these triterpenes from the olive skin. Consequently, they are found in virgin olive oil at concentrations of 194 (SE 14) $\mathrm{mg} / \mathrm{kg}$ for maslinic acid and 244 (SE 28) $\mathrm{mg} / \mathrm{kg}$ for oleanolic acid ${ }^{(6)}$.

Pentacyclic triterpenoids are abundant in the plant kingdom, and have been widely used for medicinal purposes in many Asian countries ${ }^{(7)}$. Maslinic acid has received relatively scant attention, which can mainly be attributed to the lack of a commercial standard. Most studies have therefore used extracts from various plants used in traditional Asian medicine that contained not only maslinic acid. However, maslinic acid has been described as an anti-HIV agent ${ }^{(8)}$, as an antioxidant $^{(9)}$, anti-inflammatory ${ }^{(10)}$ and anti-tumoral agents ${ }^{(11,12)}$. Oleanolic acid, whose chemical structure differs from maslinic acid by the lack of the hydroxyl group at the 2-carbon position, is a well-known member of the oleanane triterpene family. The myriad of biological and pharmacological properties described for oleanolic acid include, among others, anti-inflammatory, anti-tumoral, hepatoprotective, anti-diabetogenic and anti-HIV activities ${ }^{(7,13)}$.

Colon cancer development is often characterized in an early stage by a hyperproliferation of the epithelium leading to the formation of adenomas. In this multi-step process an early intervention $^{(14)}$ should target the inhibition of enhanced cell proliferation in transformed cells and, probably more important, the induction of the apoptotic pathway to delete cells carrying mutations. Both processes were shown to be modulated by an olive fruit extract composed of $73.25 \%$ maslinic and $25.75 \%$ oleanolic acid ${ }^{(3)}$.We here present data on the effects of the individual constituents in a human colorectal cancer 
Maslinic acid<smiles>CC1(C)CC[C@]2(C(=O)O)CC[C@]3(C)C(=CCC4[C@]3(C)CC[C@]3(C)C(C)(C)[C@@H](O)[C@H](O)C[C@]43C)[C@@H]2C1</smiles>

\section{Experimental methods}

\section{Chemicals and reagents}

Maslinic acid was obtained from olive pomace according to the patented method from García-Granados ${ }^{(15)}$ and was kindly provided by V. R.-G. from the Instituto de la Grasa, Sevilla. Oleanolic acid was purchased from Extrasynthese (Geney, France). Media and supplements for cell culture were from Invitrogen (Karslruhe, Germany). Cell culture plates were from Renner (Dannstadt, Germany) and Quadriperm ${ }^{\circledR}$ wells were obtained from Merck (Darmstadt, Germany). The fluorophores SYTOX-Green, MitoTracker Red CMXRos and proxyl fluorescamine were from Invitrogen. Hoechst dyes were purchased from Sigma (Deisenhofen, Germany) and the fluorogenic caspase-3 substrate acetyl-aspartyl-glutamyl-valyl-aspartylamino-4-methyl-coumarine was obtained from Calbiochem (Bad Soden, Germany).

\section{Cell culture}

HT-29 cells (passage 106) were provided by American Type Culture Collections and were used between passages 150 and 200. Cells were cultured and passaged in RPMI 1640 supplemented with $100 \mathrm{ml} / \mathrm{l}$ fetal calf serum and $2 \mathrm{mmol} / \mathrm{l}$ glutamine. Antibiotics added to the media were $100000 \mathrm{U} / \mathrm{l}$ penicillin and $100 \mathrm{mg} / \mathrm{l}$ streptomycin. The cultures were maintained in a humidified atmosphere of $95 \%$ air and $5 \% \mathrm{CO}_{2}$ at $37^{\circ} \mathrm{C}$. Fresh medium was given every $2 \mathrm{~d}$ and on the day before the experiments were performed. Cells were passaged at preconfluent densities by the use of a solution containing $0.05 \%$ trypsin and $0.5 \mathrm{~mm}$-EDTA. Maslinic acid and oleanolic acid were applied to the cell cultures dissolved in dimethyl sulphoxide (DMSO) to a final concentration of $2 \%(\mathrm{v} / \mathrm{v})$ in all the experiments. Controls were always treated with the same amount of DMSO.

\section{Necrosis}

The potential non-specific toxicity of maslinic and oleanolic acid in HT-29 cells was assessed prior to the study. Therefore, HT-29 cells were seeded at a density of $5 \times 10^{4}$ cells/well on to twenty-four-well cell culture plates and allowed to adhere for $4 \mathrm{~h}$. Subsequently, the medium was replaced by a fresh one and the cells were exposed for $3 \mathrm{~h}$ to increasing concentrations of each compound. Necrotic cell death was evaluated with SYTOX-Green, which becomes fluorescent after DNA binding. The percentage of dead cells was determined by SYTOX-fluorescence prior to cell lysis in relation to the fluorescence measured after the solubilization of cells with $1 \%$ $(\mathrm{v} / \mathrm{v})$ Triton X-100 in isotonic $\mathrm{NaCl}$. Cell numbers were determined based on a calibration curve measured using cell numbers between $1 \times 10^{3}$ and $1.5 \times 10^{5}$ cells, which had been adjusted after counting the cells in a Neubauer chamber. Fluorescence was measured at $538 \mathrm{~nm}$ after excitation at $485 \mathrm{~nm}$ using a fluorescence multiwell-plate reader (Fluoroskan Ascent; Thermo Electron, Dreieich, Germany).

\section{Cell proliferation}

In the proliferation assay HT-29 cells were seeded at a density of $5 \times 10^{3}$ cells/well on to twenty-four-well cell culture plates and allowed to adhere for $24 \mathrm{~h}$. Thereafter, medium was replaced by a fresh culture medium containing increasing concentrations of maslinic or oleanolic acid. Cells were allowed to grow for another $72 \mathrm{~h}$ and total cell counts were determined thereafter. Cells were lysed with $1 \%$ (v/v) Triton X-100 in isotonic $\mathrm{NaCl}$ and DNA was stained with SYTOX-Green. Cell numbers were counted using the fluorescence multiwell-plate reader.

\section{Caspase-3-like activity}

Caspase-3-like activity was measured following the method of Nicholson et al. ${ }^{(16)}$ and used as an early apoptosis marker. Briefly, cells were seeded at a density of $5 \times 10^{5}$ per well on to six-well plates and allowed to adhere for $24 \mathrm{~h}$. HT- 29 cells were exposed to 150 and $250 \mu \mathrm{mol} / \mathrm{l}$ maslinic and oleanolic acids at different time-points: $3,8,12,24,36$ and $48 \mathrm{~h}$. Cells were trypsinized once the incubation was finished. Cell numbers were determined, and cells were centrifuged at $2500 \mathrm{~g}$ for $10 \mathrm{~min}$. Cytosolic extracts were prepared by adding $750 \mu \mathrm{l}$ of a buffer containing $2 \mathrm{mmol} / \mathrm{l}$ EDTA, $1.63 \mu \mathrm{mol} / 1$ 3-((cholamidopropyl)-dimethyl-ammonium)1-propane-sulphonate, $5 \mathrm{mmol} / \mathrm{l}$ dithiothreitol, $1 \mathrm{mmol} / \mathrm{l}$ phenylmethyl-sulphonyl-fluoride, $10 \mathrm{mg} / \mathrm{l}$ pepstatin $\mathrm{A}, 20 \mathrm{mg} / \mathrm{l}$ leupeptin, $10 \mathrm{mg} / \mathrm{l}$ aprotinin and $10 \mathrm{mmol} / \mathrm{l} \mathrm{HEPES} / \mathrm{KOH}(\mathrm{pH} 7.4)$ to each pellet and homogenized with ten strokes. The homogenate was centrifuged at $100000 \mathrm{~g}$ at $4^{\circ} \mathrm{C}$ for $30 \mathrm{~min}$, and the cytosolic supernatant was incubated with the fluorogenic caspase- 3 tetrapeptide-substrate acetyl-aspartyl-glutamyl-valyl-aspartyl-amino-4-methyl-coumarine 
at a final concentration of $20 \mu \mathrm{mol} / \mathrm{l}$. Cleavage of the caspase- 3 substrate was followed by determination of emission at $460 \mathrm{~nm}$ after excitation at $390 \mathrm{~nm}$ using the fluorescence plate reader. The study of the time-dependent activation of caspase- 3 indicated that $24 \mathrm{~h}$ was the optimal incubation time. Consequently, the dosedependent activation of this caspase was evaluated after HT-29 cells had been incubated for $24 \mathrm{~h}$ with maslinic and oleanolic acids.

\section{Detection of superoxide radicals}

Production of superoxide radicals in mitochondria of HT-29 cells was visualized using a confocal laser scanning microscope (Leica TCS SP2, Bensheim, Germany). Therefore, cells were seeded at a density of $3 \times 10^{4}$ per well on glass slides placed in Quadriperm ${ }^{\circledR}$ wells. Cells were grown for $24 \mathrm{~h}$ to allow adhesion to the slides. Subsequently, medium was replaced by a fresh one containing $150 \mu \mathrm{mol} / \mathrm{l}$ maslinic acid or $150 \mu \mathrm{mol} / \mathrm{l}$ oleanolic acid and cells were incubated for $4 \mathrm{~h}$. Proxyl fluorescamine $(50 \mu \mathrm{mol} / \mathrm{l})$ was loaded to the cells for the last $2 \mathrm{~h}$ of incubation with the aim of determining the production of superoxide anions in the mitochondria. Mitochondria were stained with $500 \mathrm{nmol} / 1$ MitoTracker Red CMXRos, which was loaded to the cells for the last $30 \mathrm{~min}$ of incubation. Superoxide radicals were detected after excitation with the UV laser at emissions of $440-480 \mathrm{~nm}$ and mitochondria were visualized after excitation at $543 \mathrm{~nm}$ at emissions of 590-650 $\mathrm{nm}$, respectively.

\section{Membrane permeability}

HT-29 cells were seeded at a density of $3 \times 10^{4}$ cells/well on glass slides placed in Quadriperm ${ }^{\circledR}$ wells and allowed to adhere for $24 \mathrm{~h}$. Afterward, culture medium was replaced with a fresh one containing $150 \mu \mathrm{mol} / \mathrm{l}$ maslinic acid and cells were incubated for $8,16,20$ and $24 \mathrm{~h}$. At the end of the incubation, cells were stained with $1 \mathrm{mg} / \mathrm{l}$ Hoechst 33342 and the rate of accumulation of the dye in early apoptotic cells ${ }^{(17)}$ was detected using an inverted fluorescence microscope (Leica DMIRBE, Bensheim, Germany) equipped with a band-pass excitation filter of $340-380 \mathrm{~nm}$ and a long-pass emission filter of $425 \mathrm{~nm}$. Photographs were taken of at least three independent cell batches, and images were evaluated on a blindly coded basis. Apoptotic cells were determined by the number of cells showing elevated fluorescence versus the total cell counts.

\section{Nuclear fragmentation}

Nuclear fragmentation as a late marker of apoptosis was determined by the staining of DNA with Hoechst 33258. HT-29 cells $\left(3 \times 10^{4}\right.$ cells/well) were seeded on glass slides, allowed to adhere for $24 \mathrm{~h}$, and were incubated with $150 \mu \mathrm{mol} / \mathrm{l}$ maslinic acid during 8, 16, 20 and $24 \mathrm{~h}$. After each time-point, cells were washed with PBS, allowed to air-dry for $30 \mathrm{~min}$ and then were fixed with $2 \%$ paraformaldehyde before staining with $1 \mathrm{mg} / \mathrm{l}$ Hoechst 33258. Cells were visualized under the inverted fluorescence microscope at emission of $425 \mathrm{~nm}$ after excitation of $340-280 \mathrm{~nm}$. Images were evaluated on a blindly coded basis. Apoptotic cells were determined by the number of cells displaying chromatin condensation and nuclear fragmentation versus total cell counts.

\section{Statistics}

Results are expressed as means with their standard errors. To derive the $\mathrm{EC}_{50}$ values for growth inhibition, a non-linear approximation model by the least square method based on a competition curve using one component was applied. Results were tested for normal distribution and for homogeneity of variance by standardized residual plot. When necessary, logarithmic transformations were performed. Normally distributed results were analysed by one-way ANOVA. If the result was found to be significant $(P<0.05)$ the Tukey's multiple comparison test was used to determine specific differences between results. Statistical differences between time and dose were tested by two-way ANOVA and Bonferroni's post-test. The effects with $P<0.05$ were considered statistically significant. All statistical analyses were performed using GraphPad Prism (GraphPad Software, San Diego, CA, USA).

\section{Results}

Necrosis

Maslinic acid did not exert non-specific cytotoxicity at the concentration range from 1 to $250 \mu \mathrm{mol} / \mathrm{l}$ since $95 \cdot 3$ (SE $0 \cdot 2$ )
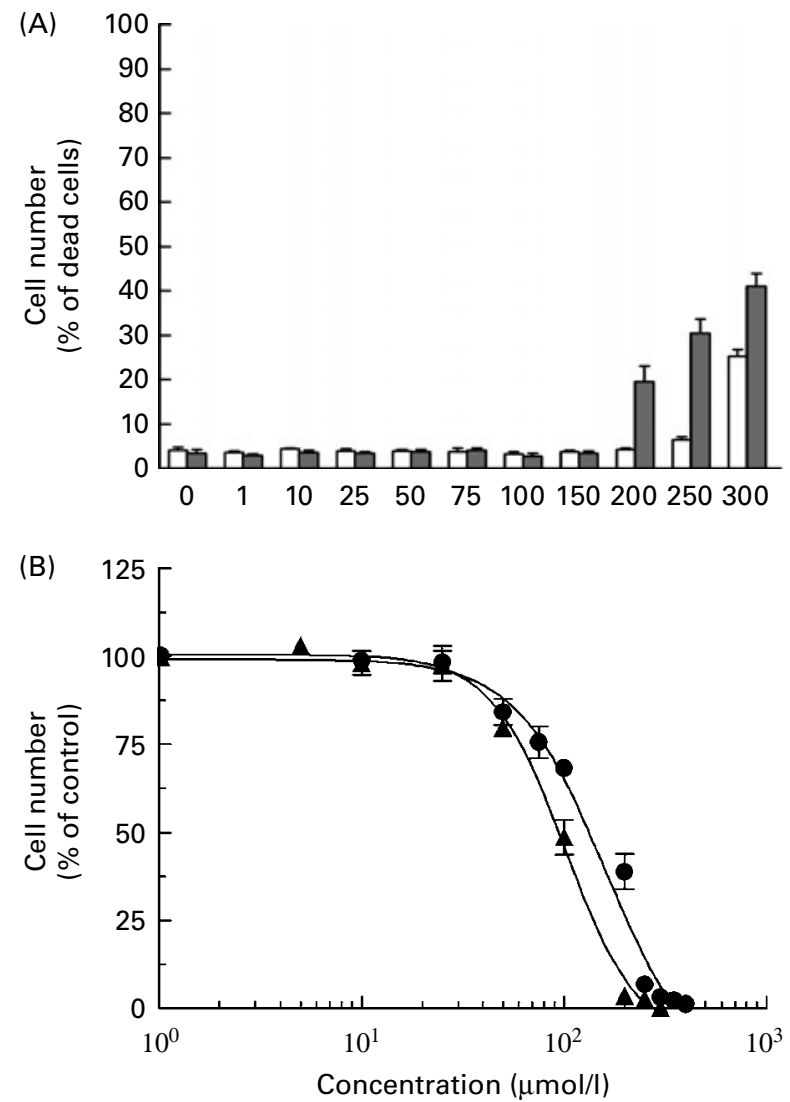

Fig. 2. Effects of maslinic and oleanolic acids on proliferation and necrosis in HT-29 cells. (A), Proliferation was measured over $72 \mathrm{~h}$ in the absence (control) or presence of compounds at different concentrations $(\square$, maslinic acid; $\mathbf{\square}$, oleanolic acid). (B), Necrosis was assessed after incubating the cells for $3 \mathrm{~h}$ with medium alone (control) or containing different concentrations of compounds ( $\boldsymbol{\Lambda}$, maslinic acid; $\bullet$, oleanolic acid). Values are means with their standard errors depicted by vertical bars. 
$\%$ of the cells were viable even at $250 \mu \mathrm{M}$ (Fig. 2 (A)). Only at $300 \mu \mathrm{mol} / \mathrm{l}$ was the number of living cells reduced to 74.6 (SE 1.4$) \%(P<0.0001)$ within $3 \mathrm{~h}$. The viability of HT-29 cells after $3 \mathrm{~h}$ incubation with oleanolic acid at concentrations up to $150 \mu \mathrm{mol} / 1$ was 97.5 (SE $0 \cdot 3$ ) $\%$. Cell viability at concentrations of 200,250 and $300 \mu \mathrm{mol} / \mathrm{l}$ was reduced to 83.6 (SE 2.2) \%, $69.5($ SE 3.3) $\%(P<0.001)$ and $58.9($ SE 2.9$) \%$ $(P<0 \cdot 001)$, respectively.

\section{Cell proliferation}

Maslinic acid displayed dose-dependent antiproliferative activity in HT-29 cells with an $\mathrm{EC}_{50}$ of 101.2 (SE 7.8) $\mu \mathrm{mol} / 1$ (Fig. 2 (B)). Oleanolic acid also inhibited the proliferation of HT-29 cells in a dose-dependent manner but to a lesser extent. Incubation of cells for $72 \mathrm{~h}$ with 50 and $200 \mu \mathrm{mol} / \mathrm{l}$ oleanolic acid induced 16 and $62 \%$ reductions in cell number, respectively, with an overall $\mathrm{EC}_{50}$ of $160 \cdot 6$ (SE 10.6) $\mu \mathrm{mol} / 1$ (Fig. 2 (B)).

\section{Caspase-3-like activity}

When HT-29 cells were exposed to $150 \mu \mathrm{mol} / \mathrm{l}$ maslinic acid, caspase-3-like activity was induced in a time-dependent manner with a 14-fold activation between 24 and $48 \mathrm{~h}$ of exposure (Fig. 3). Maslinic acid at $250 \mu \mathrm{mol} / \mathrm{l}$ resulted in a more than 60 -fold activation of caspase- 3 at $24 \mathrm{~h}$, whereas thereafter caspase-3-like activity declined (Fig. 3 (A)).
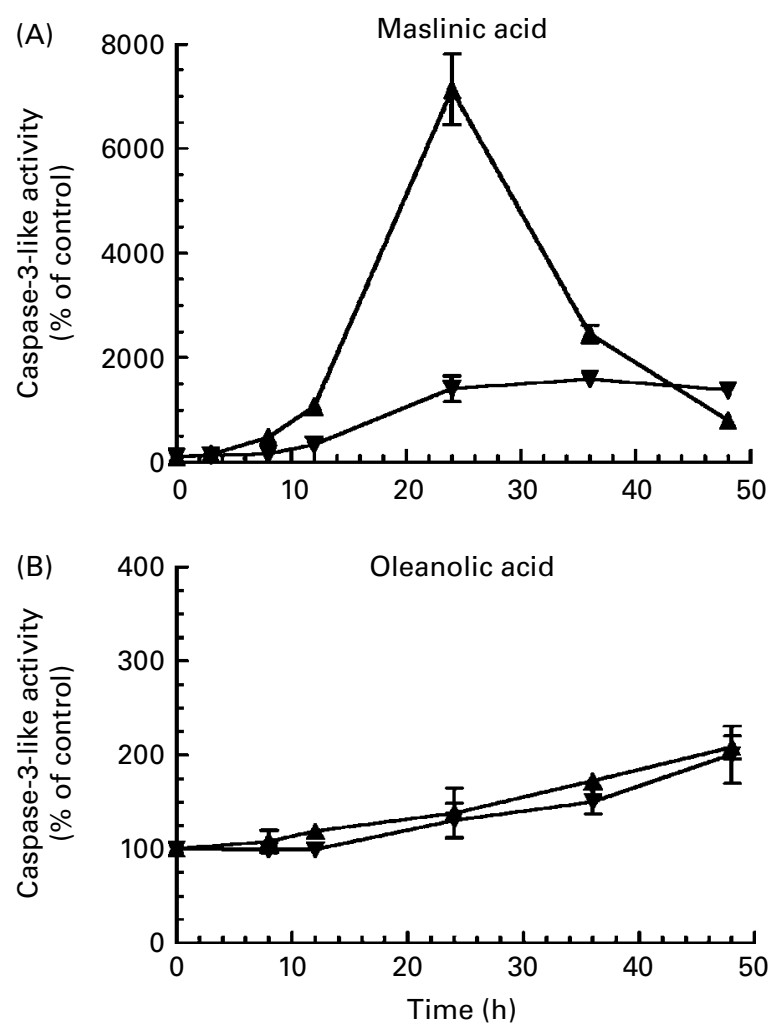

Fig. 3. Time-dependent caspase-3 activity in HT-29 cells. Caspase3 -like activity at various time-points of incubation with maslinic acid $(A)$ and oleanolic acid (B) $(\boldsymbol{\nabla}, 150 \mu \mathrm{mol} / \mathrm{l} ; \boldsymbol{\Lambda}, 250 \mu \mathrm{mol} / \mathrm{l})$ was determined by measuring cleavage of acetyl-aspartyl-glutamyl-valyl-aspartyl-amino-4-methyl-coumarine. Values are means with their standard errors depicted by vertical bars.
At concentrations of 150 or $250 \mu \mathrm{mol} / \mathrm{l}$, oleanolic acid, unlike maslinic acid, showed only moderate effects on caspase-3-like activities, with a maximum of two-fold activation at $48 \mathrm{~h}$ (Fig. 3 (B)).

When caspase-3-like activity was studied at $24 \mathrm{~h}$ as a function of maslinic acid concentration, we found a dose-dependent increase (Fig. 4 (A)). At $10 \mu \mathrm{mol} / 1$, maslinic acid stimulated caspase-3-like activity 3 -fold over the control $(P<0 \cdot 0001)$, and higher concentrations induced a steady increase in the activation (Fig. 4 (A)).

Surprisingly, oleanolic acid had no effect on caspase-3 activity at any of the times or concentrations studied in the range from 50 to $300 \mu \mathrm{mol} / \mathrm{l}$ (Fig. 4).

\section{Generation of mitochondrial reactive oxygen species}

Caspase- 3 can be activated by a death-receptor-mediated pathway but also by the mitochondrial apoptosis pathway ${ }^{(18)}$. Increased levels of mitochondrial superoxide anions have been found in many studies as an initiator of the mitochondrial apoptosis pathway ${ }^{(19)}$. Confocal microscopy analysis revealed an early increase of superoxide anion production in mitochondria of HT-29 cells treated for $4 \mathrm{~h}$ with $150 \mu \mathrm{mol} / \mathrm{l}$ maslinic acid (Fig. 5). Maslinic and oleanolic acids clearly differed in
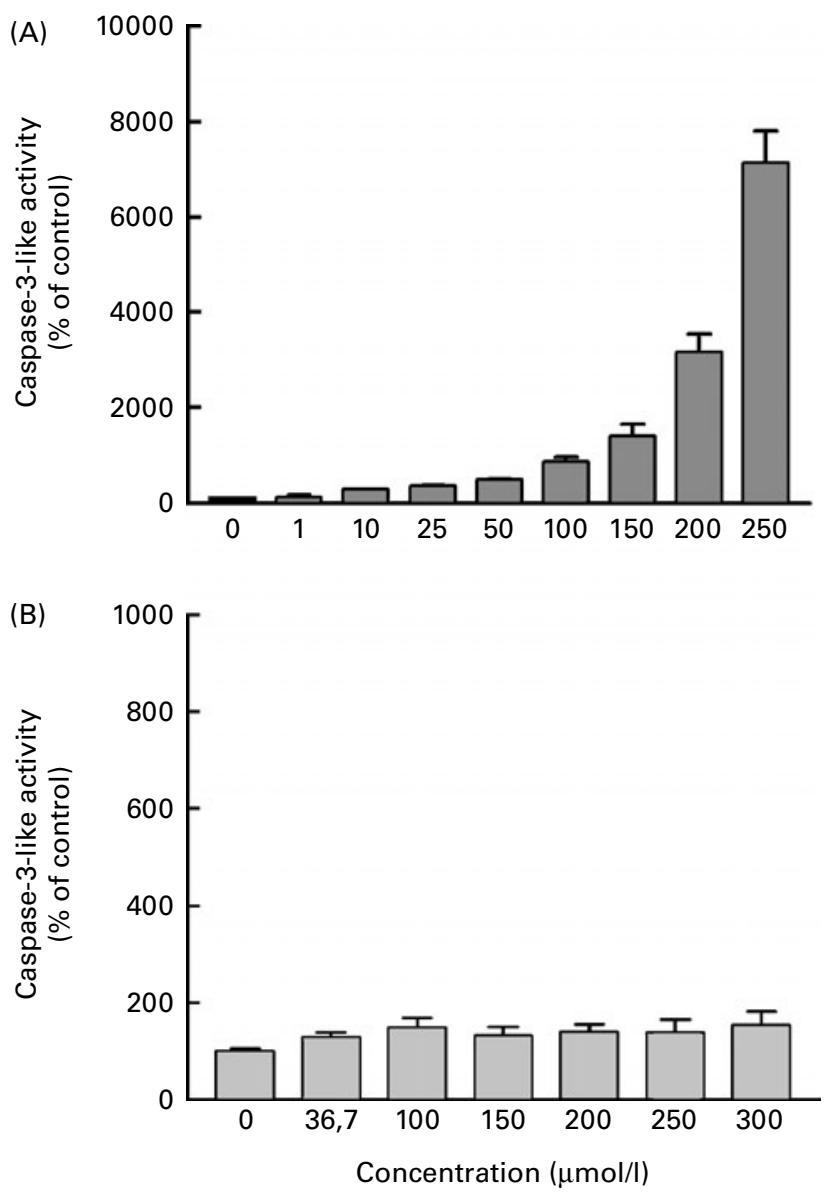

Fig. 4. Dose-dependent caspase- 3 activity in HT-29 cells. Induction of caspase-3-like activity was determined after incubations with maslinic acid $(A)$ and oleanolic acid (B) at $24 \mathrm{~h}$ based on the cleavage of the fluorogenic substrate acetyl-aspartyl-glutamyl-valyl-aspartyl-amino-4-methyl-coumarine. Values are means with their standard errors depicted by vertical bars. 


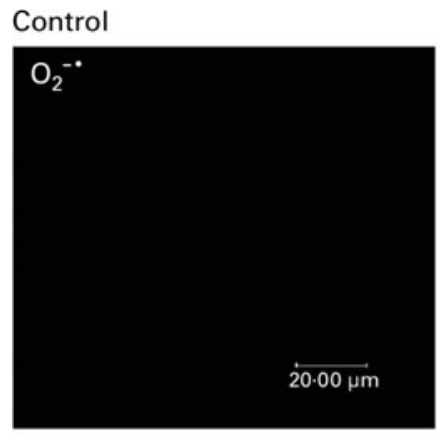

Maslinic acid
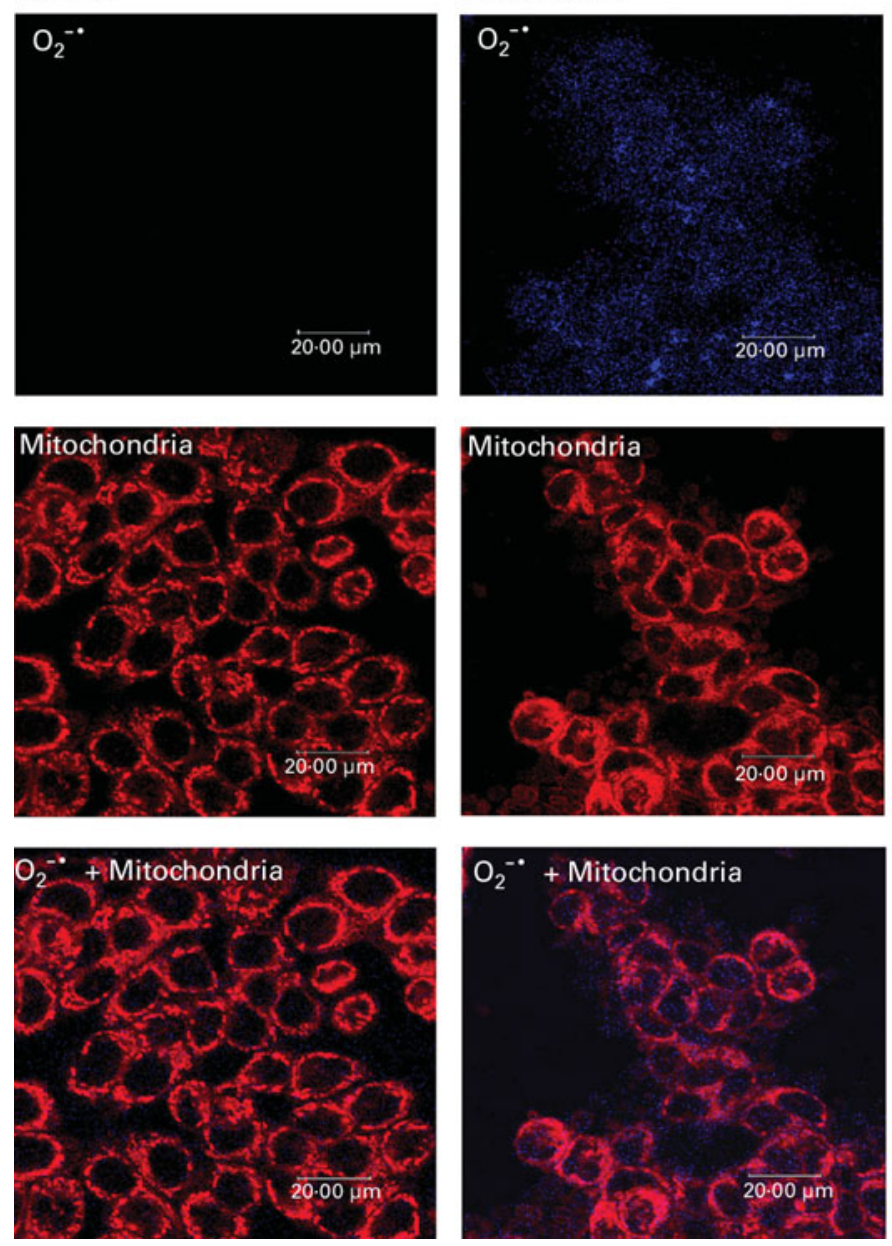
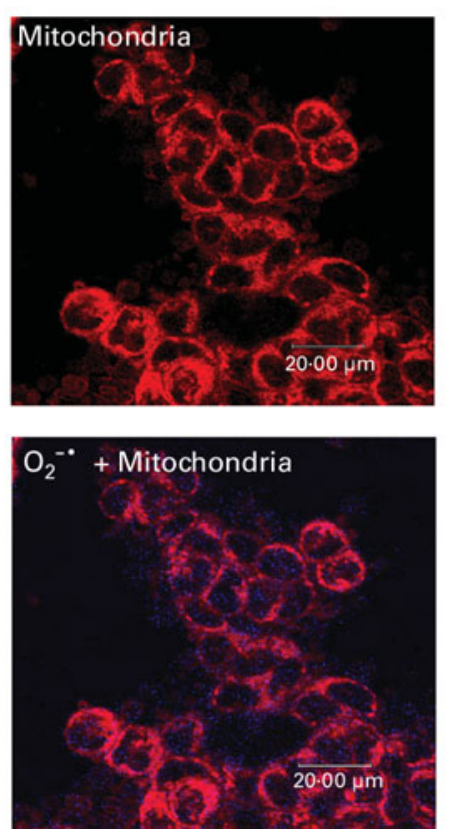

Oleanolic acid
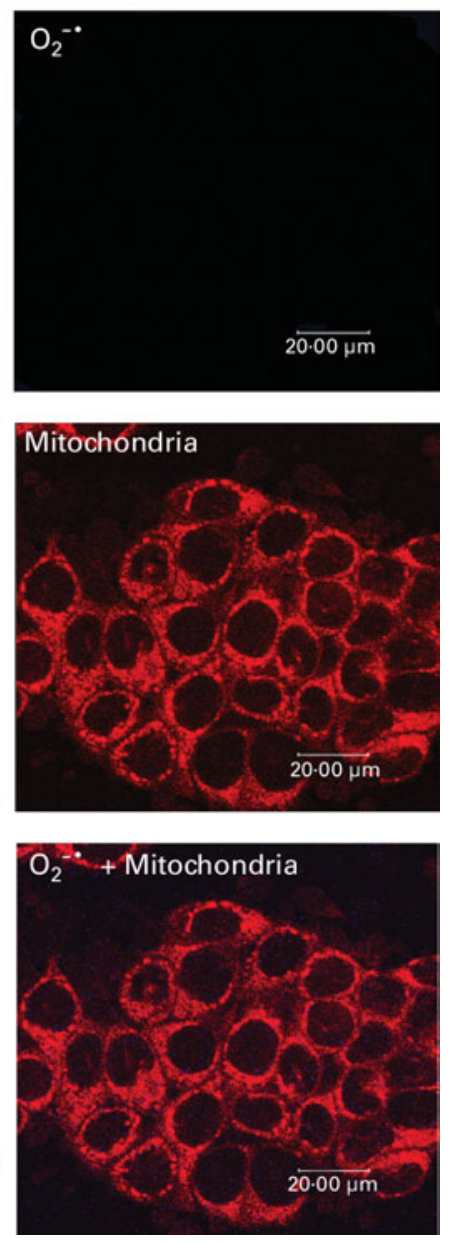

Fig. 5. Detection of superoxide radicals in the mitochondria of HT-29 cells. Cells were incubated with medium alone (control), $150 \mu \mathrm{mol} / \mathrm{l}$ maslinic acid and $150 \mu \mathrm{mol} / \mathrm{l}$ oleanolic acid. During the last period of incubation cells were loaded with proxylfluorescamine for the detection of $\mathrm{O}_{2}^{-\cdot}$ in combination with MitroTracker for the visualization of the mitochondria.

their ability to generate mitochondrial reactive oxygen species (ROS). HT-29 cells treated with $150 \mu \mathrm{mol} / \mathrm{l}$ oleanolic acid did not display any blue fluorescence which indicated the presence of $\mathrm{O}_{2}^{-}$, and were not different from control cells.

\section{Membrane permeability}

We then assessed whether activation of caspase- 3 by maslinic acid induced the morphological characteristics of apoptosis. Maslinic acid $(150 \mu \mathrm{mol} / \mathrm{l})$ increased accumulation of the Hoechst dye 33342 in HT-29 cells over time (Fig. 5). After exposing HT-29 cells to $150 \mu \mathrm{mol} / 1$ maslinic acid for $8 \mathrm{~h}$, 14.8 (SE 0.7) \% $(P<0.0001)$ of cells showed accumulation of Hoechst 33342. This accumulation increased to 49.4 (SE $2 \cdot 9) \%(P<0 \cdot 0001)$ following $24 \mathrm{~h}$ of incubation (Fig. $6(\mathrm{~A}))$.

\section{Nuclear fragmentation}

Exposure to $150 \mu \mathrm{mol} / \mathrm{l}$ maslinic acid increased the fragmentation of DNA and chromatin condensation (Fig. 6 (B)). Apoptotic bodies were detected after $8 \mathrm{~h}$ of incubation in 9.7 (SE 0.9) $\%(P<0.0001)$ of cells, and after $24 \mathrm{~h}$ nuclear fragmentation was detected in 30.8 (SE 2.9) \% $(P<0.0001)$ of HT-29 cells.

\section{Discussion}

The Mediterranean diet, which is rich in olives and olive oil, is believed to confer various health benefits including a decreased cancer risk ${ }^{(2)}$. Here we attempt to identify which of the triterpenic compounds of the olive fruit extract was responsible for its anti-tumour activity described previously ${ }^{(3)}$, and to assess whether there was an additive action.

Both maslinic and oleanolic acids reduced cell proliferation rates, with half-maximal effects for growth-inhibition of around 100-150 $\mathrm{mol} / \mathrm{l}$. However, maslinic acid did not induce necrosis even at concentrations that cause full inhibition of cell growth. Oleanolic acid reduced cell growth with lower activity and caused complete inhibition at $320 \mu \mathrm{mol} / \mathrm{l}$. This growth-inhibition may be attributed, at least in part, to cell-cycle arrest, since oleanolic acid is involved in the $G_{0} / G_{1}$ checkpoint control and the inhibition of DNA replication in the human colon carcinoma cell line $\mathrm{HCT} 15^{(20)}$. The moderate yet significant non-specific toxicity is most likely the cause of the apparent anti-proliferative activity, since at $300 \mu \mathrm{mol} / 1$ the percentage of dead cells was $40 \%$, which is in agreement with other results in the literature $(20,21)$. 
(A)
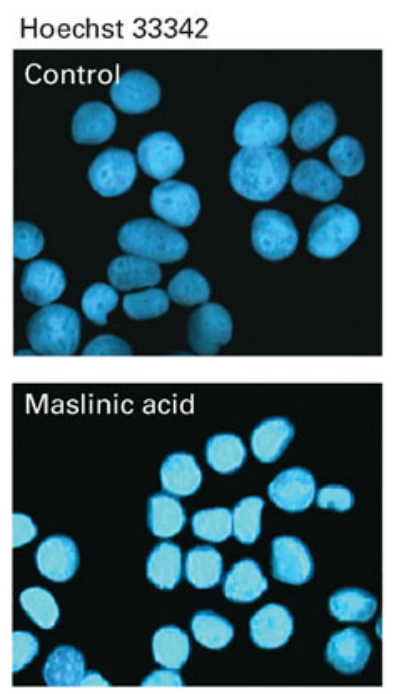

The most promising finding of the present study was the ability of maslinic acid to induce apoptosis in colonic cancer cells. It increased the activity of caspase- 3 in a timeand a dose-dependent manner, with the highest activation of 70-fold above that in control cells at a concentration of $250 \mu \mathrm{mol} / \mathrm{l}$. Oleanolic acid did not activate caspase- 3 even at the highest concentrations tested. The inability of this compound to induce apoptosis is in agreement with other studies $^{(21)}$, and was also reported for the human colon carcinoma cell line HCT15 ${ }^{(20)}$. Although oleanolic acid has been described to inhibit tumour initiation and promotion steps ${ }^{(22)}$, its overall anti-tumour activity is relatively weak ${ }^{(13)}$. For this reason, new synthetic analogues of this compound have been synthesized in order to enhance its potency ${ }^{(21,23)}$.

The present results indicate that maslinic acid can induce an activation of caspase- 3 with a superior activity to that exerted by the same concentration in the complete olive fruit extract. The lowest concentration used in the present study which corresponds to $10 \mu \mathrm{mol} / \mathrm{l}$ maslinic acid induced an activation of caspase- 3 of $300 \%$ of that in control cells. Once activated, caspases cleave a battery of cellular substrates, leading finally to morphological changes as a hallmark of apoptosis ${ }^{(18)}$. The increase in caspase-3-like activity caused by maslinic acid was followed by full execution of apoptosis control group: ${ }^{\star} P<0 \cdot 0001$.

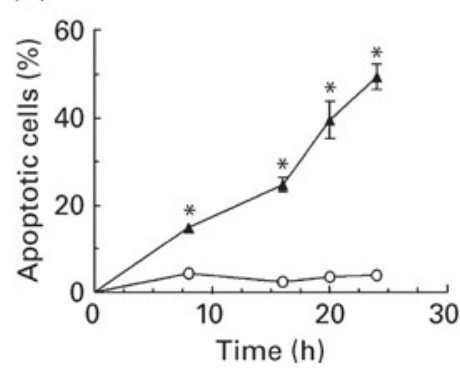

(C)
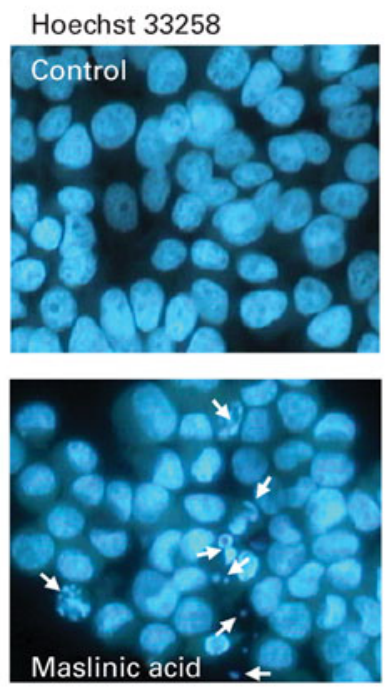

(D)

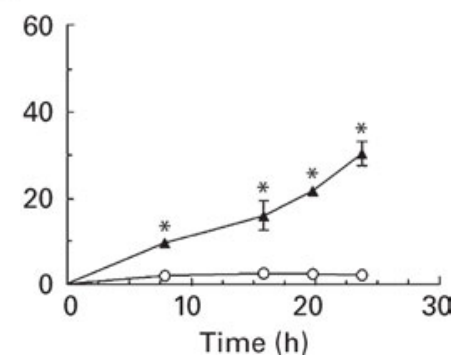

Fig. 6. Determination of early and late apoptotic events in HT-29 at different time-points. Cells that accumulated Hoechst 33352 dye due to membrane disintegration (A) were counted and expressed as the percentage of apoptotic cells (B) under control conditions $(O)$ or after $150 \mu \mathrm{mol} / \mathrm{l}$ maslinic acid treatment $(\mathbf{\Lambda})$. Cells that displayed nuclear fragmentation (C) were counted and expressed as the percentage of apoptotic cells (D) under control conditions (O) or after $150 \mu \mathrm{mol} / \mathrm{l}$ maslinic acid treatment $(\mathbf{\Lambda})$. Values are means with their standard errors depicted by vertical bars. Mean values were significantly different from those of the

with a disintegration of the plasma membrane and finally a pronounced nuclear fragmentation.

Many anticancer drugs induce apoptosis by activating intrinsic pathways that increase cellular ROS production ${ }^{(24,25)}$. Therefore, we determined ROS levels in the mitochondria of HT-29 cells treated with maslinic or oleanolic acids, and demonstrate that maslinic acid disrupts the function of mitochondria at the early stage of apoptosis induction. HT-29 cells exposed to maslinic acid showed markedly increased levels of superoxide anion radicals in mitochondria. On the other hand, the failure to generate superoxide anions in mitochondria of oleanolic acid-treated cells may explain the lack of apoptotic activity shown by this triterpene. ROS production occurs in an early phase suggesting that maslinic acid triggers a rapid release of cytochrome $c$ from mitochondria into the cytosol that in turn activates procaspase- 9 and the downstream effectors, including the pro-caspases $-3,-6$ and -7 , followed finally by the cleavage of proteins and DNA that characterize the final phase of apoptosis. ROS can affect divergent cellular functions depending on the cellular level and their compartmentation. Mitochondria are the primary cellular site of ROS production and, under certain conditions, elevated mitochondrial ROS levels can serve as pro-apoptotic signals ${ }^{(26)}$. As enzymatic and/or non-enzymatic antioxidant systems control 
ROS levels, the balance of ROS production and their removal in a given cell type is most critical also for the elimination of transformed cells that when allowed to bypass apoptotic elimination can lead to solid tumours. Dietary constituents promoting mitochondrial ROS production could be as important in cancer prevention as dietary antioxidants.

Maslinic and oleanolic acids are highly lipophilic molecules. In order to overcome their water insolubility, these pentacyclic triterpenes were dissolved in $2 \%(\mathrm{v} / \mathrm{v}) \mathrm{DMSO}$, a percentage previously used ${ }^{(3)}$. Although DMSO is normally used at $1 \%$, with very highly lipophilic compounds, the percentage of DMSO can be safely increased to $5 \%$, given that it has been reported that it may be used without any significant cell damage, after an exposure of $2 \mathrm{~h}$, up to $10 \%$ in Caco 2 cells ${ }^{(27)}$. DMSO may also possess other activities, such as antioxidant activity. For this reason and in order to minimize the effect of DMSO, the same amount both in the control and in the treated cells was employed in all the assays.

Induction of apoptosis in precancerous cells may provide protection against cancer development and therefore, may provide the basis for a novel nutritional strategy for cancer prevention. The practical implication is that consumption of diets containing maslinic acid in the form of olives or olive oil may trigger precancerous cells to die by apoptosis. The concept of dietary chemoprevention is usually applied in the context of protecting normal cells from initiating events that introduce oncogenic mutations. However, substantial literature is available to show that carcinogenesis represents a progression of cellular changes ${ }^{(28)}$, and agents that disrupt this progression at any point can be considered chemopreventive. The HT-29 cells used in the present study represent a model of an advanced stage of tumour development. Therefore, we consider it especially significant that maslinic acid induced apoptosis in these cells at concentrations that may be achieved with a normal diet.

For any chemopreventive activity of a dietary constituent the intake via the relevant foods must be sufficient to attain the cellular concentrations that display the bioactivity. According to data from the literature, the mean daily consumption of table olives and olive oil in the Mediterranean area corresponds to approximately $40 \mathrm{~g}$ or ten mediumsized olives and $33 \mathrm{~g}$ oil. Consequently, in the Mediterranean basin the regular consumption of olives and olive oil could provide an average daily intake of maslinic acid of approximately $34 \mathrm{mg} / \mathrm{d}$. There is no information indicating the metabolic fate of maslinic acid either in man or in cell culture. Recently the pharmacokinetics of oleanolic acid in rats has been reported ${ }^{(29)}$, with an absolute oral bioavailability of $0.7 \%$ for the administrations of 25 and $50 \mathrm{mg} / \mathrm{kg}$. The extent of urinary excretion was minimal for oral doses, indicating the oral bioavailability of oleanolic acid could be due to a poor absorption, therefore, the intestinal epithelium is exposed to high concentrations of these compounds. Assuming that $30 \%$ of this compound is not absorbed in the small intestine and reaches the colon unaltered, its distribution with an assumed volume of around $250 \mathrm{ml}$ would result in maslinic acid concentrations as high as $86 \mu \mathrm{mol} / \mathrm{l}$ - a concentration that was proven to be sufficient to initiate apoptosis. Based on the same assumption and taking into account the amount of oleanolic acid present in olives and olive oil, this compound would reach a colonic concentration of around $60 \mu \mathrm{mol} / \mathrm{l}$. With a normal diet, these colonic oleanolic acid concentrations would most likely not result in cytotoxicity or anti-proliferative activity. Moreover, oleanolic acid has already been shown to have a low side-effect profile as demonstrated in toxicity experiments conducted in mice and rats $^{(22)}$.

In conclusion, we demonstrate that the naturally occurring pentacyclic triterpene, maslinic acid, is the responsible compound in an olive extract that was shown to inhibit colon cancer cell growth ${ }^{(3)}$. Maslinic acid inhibits cellular proliferation at non-toxic concentrations and more importantly restores apoptosis sensitivity in human colon adenocarcinoma cells. Given that apoptosis induction is arguably the most important process to remove cells that have lost growth control, maslinic acid appears as a promising new chemical entity in the diet with a cancer-chemopreventive activity. What is surprising is that the presence of one hydroxyl group in the chemical structure of maslinic acid as compared to oleanolic causes these different biological activities.

\section{Acknowledgements}

Supported by grant AGL2005-05728 from the Ministerio de Ciencia y Tecnología and grant 2005-SGR-00632 from the Generalitat de Catalunya, Spain. The authors declare no conflict of interest. M. E. J., U. W., H. D. and J. M. P. contributed to the experimental design, discussion and writing of the manuscript. M. E. J. performed the research. V. R.-G. provided maslinic acid.

\section{References}

1. Simopoulos AP (2001) The Mediterranean diets: what is so special about the diet of Greece? The scientific evidence. J Nutr 131, 3065S-3073S.

2. Owen RW, Haubner R, Wurtele G, Hull E, Spiegelhalder B \& Bartsch H (2004) Olives and olive oil in cancer prevention. Eur J Cancer Prev 13, 319-326.

3. Juan ME, Wenzel U, Ruiz-Gutierrez V, Daniel H \& Planas JM (2006) Olive fruit extracts inhibit proliferation and induce apoptosis in HT-29 human colon cancer cells. J Nutr 136, 2553-2557.

4. Vioque E \& Maza MP (1963) On triterpenic acids from olive and olive pomace oils. Grasas Aceites 14, 9-11.

5. Bianchi G, Pozzi N \& Vlahov G (1994) Pentacyclic triterpene acids in olives. Phytochemistry 37, 205-207.

6. Pérez-Camino MC \& Cert A (1999) Quantitative determination of hydroxyl pentacyclic triterpene acids in vegetable oils. J Agric Food Chem 47, 1558-1562.

7. Ovesna Z, Vachalkova A, Horvathova K \& Tothova D (2004) Pentacyclic triterpenic acids: new chemoprotective compounds. Minirev Neoplasma 51, 327-333.

8. Xu HX, Zeng FQ, Wan M \& Sim KY (1996) Anti-HIV triterpene acids from Geum japonicum. J Nat Prod 59, 643-645.

9. Montilla MP, Agil A, Navarro MC, Jimenez MI, García-Granados A, Parra A \& Cabo MM (2003) Antioxidant activity of maslinic acid, a triterpene derivative obtained from Olea europea. Planta Med 69, 472-474.

10. Marquez-Martin A, de la Puerta Vazquez R, Fernandez-Arche A \& Ruiz-Gutierrez V (2006) Suppressive effect of maslinic acid 
from pomace olive oil on oxidative stress and cytokine production in stimulated murine macrophages. Free Radic Res 40, 295-302.

11. Kim YK, Yoon SK \& Ryu SY (2000) Cytotoxic triterpenes from sterm bark of Physocarpus intermedius. Planta Med 66, 485-486.

12. Juan ME, Wenzel U, Ruiz-Gutierrez V, Planas JM \& Daniel H (2005) Maslinic acid, a natural compound from olives, induces apoptosis in HT-29 human colon cancer cell line. FASEB J 19, A996.

13. Liu J (2005) Oleanolic acid and ursolic acid: research perspectives. J Ethnopharmacol 100, 92-94.

14. Hawk ET, Umar A \& Viner JL (2004) Colorectal cancer chemoprevention - an overview of the science. Gastroenterology 126, $1423-1447$.

15. García-Granados A (1997) Process for the industrial recovery of oleanolic and maslinic acids contained in the olive milling byproducts. Patent: PCT/ES97/000190.

16. Nicholson DW, Ali A, Thornberry NA, et al. (1995) Identification and inhibition of the ICE/CED-3 protease necessary for mammalian apoptosis. Nature 376, 37-43.

17. Elstein KH \& Zucker RM (1994) Comparison of cellular and nuclear flow cytometric techniques for discriminating apoptotic subpopulations. Exp Cell Res 211, 322-331.

18. Hengartner MO (2000) The biochemistry of apoptosis. Nature 407, 760-770.

19. Herrera B, Alvarez AM, Sanchez A, Fernandez M, Roncero C, Benito M \& Fabregat I (2001) Reactive oxygen species (ROS) mediates the mitochondrial-dependent apoptosis induced by transforming growth factor (beta) in fetal hepatocytes. FASEB $J$ 15, 741-751.
20. Li J, Guo WJ \& Yang QY (2002) Effects of ursolic acid and oleanolic acid on human colon carcinoma cell line HCT15. World J Gastroenterol 8, 493-495.

21. Assefa H, Nimrod A, Walker L \& Sindelar R (1999) Synthesis and evaluation of potential complement inhibitory semisynthetic analogs of oleanolic acid. Bioorg Med Chem Lett 9, 1889-1894.

22. Liu J (1995) Pharmacology of oleanolic acid and ursolic acid. $J$ Ethnopharmacol 49, 57-68.

23. Suh N, Wang Y, Honda T, et al. (1999) A novel synthetic oleanane triterpenoid, 2-cyano-3,12-dioxoolean-1,9-dien-28-oic acid, with potent differentiating, antiproliferative, and antiinflammatory activity. Cancer Res 59, 336-341.

24. Kroemer G \& Reed JC (2000) Mitochondrial control of cell death. Nat Med 6, 513-519.

25. Herr I \& Debatin KM (2000) Cellular stress response and apoptosis in cancer cell therapy. Blood 98, 513-519.

26. Wenzel U, Nickel A, Kuntz S \& Daniel H (2004) Ascorbic acid suppresses drug-induced apoptosis in human colon cancer cells by scavenging mitochondrial superoxide anions. Carcinogenesis 25, 703-712.

27. Da Violante G, Zerrouk N, Richard I, Provot G, Chaumeil JC \& Arnaud P (2002) Evaluation of the cytotoxicity effects of dimethyl sulfoxide (DMSO) on Caco2/TC7 colon tumor cell cultures. Biol Pharm Bull 25, 1600-1603.

28. Vogelstein B \& Kinzler KW (2004) Cancer genes and the pathways they control. Nat Med 10, 789-799.

29. Jeong DW, Kim YH, Kim HH, Ji HY, Yoo SD, Choi WR, Lee SM, Han CK \& Lee HS (2007) Dose-linear pharmacokinetics of oleanolic acid after intravenous and oral administration in rats. Biopharm Drug Dispos 28, 51-57. 